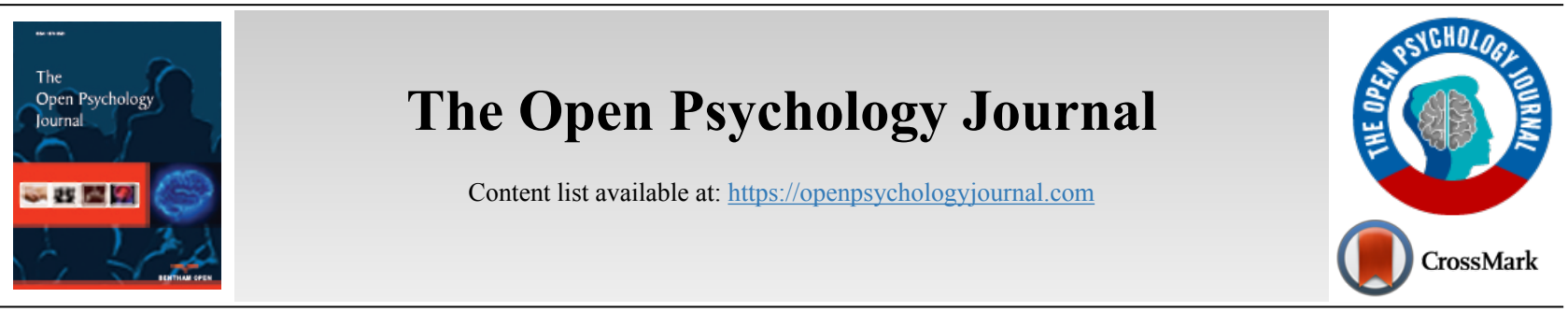

\title{
LETTER
}

\section{Cognitive Examination In Thalassemia Patients}

\author{
Uni Gamayani $^{1, *}$, Chandra Calista ${ }^{1}$, Anam Ong ${ }^{1}$, Pandji Irani Fianza ${ }^{2}$ and Ramdan Panigoro ${ }^{3}$

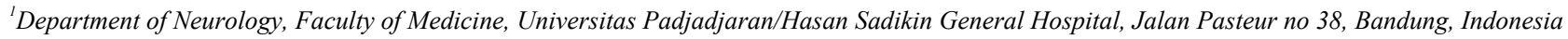 \\ ${ }^{2}$ Department of Internal Medicine, Faculty of Medicine, Universitas Padjadjaran/Hasan Sadikin General Hospital, Jalan Pasteur no 38, Bandung, \\ Indonesia \\ ${ }^{3}$ Department of Biomedical Science, Faculty of Medicine, Universitas Padjadjaran/ Hasan Sadikin General Hospital, RSP Unpad, Jalan Eijkman No \\ 38, Bandung, Indonesia
}

\begin{abstract}
:
Background:

Many studies on thalassemia patients have shown cognitive decline that may affect the patients' life. To clarify the cognitive value in thalassemia patients, we performed a neuropsychological test on these patients.

\section{Methods:}

This was a prospective observational analytic with case control study involving 40 thalassemia patients and 40 controls similar for age, sex, and education. All subjects underwent a comprehensive neuropsychological test including visual cognitive assessment.

Results:

Compared to controls, patients with thalassemia aged 15-47 years old had poorer results in world list recall ( $\mathrm{p}=0.026)$, TMT-B ( $\mathrm{p}=0.042)$, clock drawing test $(\mathrm{p}=0.049)$, ADAS-Cog $(\mathrm{p}=0.014)$, logical memory $(\mathrm{p}=0.001)$ and digit symbol $(\mathrm{p}<0.001)$. These results indicate that thalassemia patients have significantly lower attention, verbal memory capability, and executive function.

\section{Conclusion:}

Our findings concluded that patients with thalassemia have impaired multiple cognitive domains.
\end{abstract}

Keywords: Cognitive decline, Neuropsychological test, Thalassemia, Hemoglobin, Multiple cognitive domains, Attention.

\begin{tabular}{|l|l|l|l}
\hline Article History & Received: December 09, 2019 & Revised: March 09, 2020 & Accepted: April 10, 2020
\end{tabular}

\section{INTRODUCTION}

Thalassemia refers to the inherited defects in the rate of synthesis of one or more of the globin chains of hemoglobin [1]. Thalassemia and hemoglobin $(\mathrm{Hb})$ variant are the most common genetic disorders in Southeast Asia. The prevalence of thalassemia in Indonesia is quite high. Based on the Mean Corpuscular Hemoglobin (MCH), the frequency of $\alpha^{\circ}$ thalassemia carrier among Javanese, Sumatra and Sulawesi population was $2.6-3.2 \%$ and the frequency of $-\alpha+$ thalassemia carrier in the Javanese, South Sumatra and South Sulawesi population was $2.7 \%, 10 \%$ and $11 \%$, respectively [2].

Thalassemia patients require regular blood transfusions

\footnotetext{
"Address correspondence to this author at the Department of Neurology, Faculty of Medicine, Universitas Padjadjaran/ Hasan Sadikin General Hospital, Jalan Pasteur no 38, Bandung, Indonesia, E-mail: gamayani@yahoo.com
}

and have to adhere to iron chelation protocols in order to minimize iron overload complications [3]. The life expectancy of thalassemia patients has markedly improved over the last few decades, but patients still suffer from many complications of their congenital chronic disease, and treatment, including neurological complications $[4,5]$.

Various mechanisms have been studied that lead to neurological complications such as coagulopathy, chronic hypoxia caused by prolonged anemia and iron deposition in the brain [5 - 8].

The introduction of safe transfusion practices, iron chelation therapy, aggressive treatment of infections and improved management of cardiac complications has dramatically improved the life expectancy of thalassemia patients $[4,9-11]$. 
The aim of this study was to evaluate cognitive functioning in thalassemia patients with an extensive neuropsychological test

\section{METHODS}

\subsection{Participants and Recruitment}

This was a prospective observational analytic with case control study conducted in the Memory Clinic of Dr. Hasan Sadikin General Hospital, Bandung, Indonesia. The thalassemia patients were recruited from outpatient clinic patients of Hematology Oncology Medic Clinic of Dr. Hasan Sadikin General Hospital, Bandung, Indonesia between November 2017 until April 2018. The Institutional Ethics Committee approved the protocol of the study.

Inclusion criteria of this study were patients who have already been diagnosed with thalassemia, undergone regular transfusion in the Hematology Oncology Medic Clinic of Dr. Hasan Sadikin General Hospital, Bandung, Indonesia. While controlled subjects were obtained from healthy individuals with similar age, sex, and education as those of the thalassemia patients.

Patients who had hearing disturbances, history of infectious diseases, chronic health conditions, central nervous system infections, head injuries, intracranial tumors, epilepsy, and other intracranial lesions based on information collected from the medical report, parental report, and routine neurological examination were excluded from this study.

All eligible subjects were consecutively approached as they came in for their regular transfusion schedule at the outpatient clinic of the Hematology Oncology Medic Clinic during the data collection period. Written informed consent was obtained prior to participation in the study. At the beginning of the examination and interview, all respondents were informed of the objectives of the study and were assured that all responses would be kept confidential.

\subsection{Instruments}

Patients and controls were submitted to an extensive standardized neuropsychological test, exploring attention, language, verbal and visual memory, visuospatial and executive function. All subjects were evaluated in our memory clinic. The duration of the test session was approximately 2 hours.

Trail Making Test (TMT) A, vigilance test, digit span and digit symbol were used to evaluate attention. Verbal fluency and Boston naming test were used to evaluate language. Word list memory test, word list recall, word list recognition and logical memory were assessed to evaluate verbal memory while recall constructional was used to evaluate visual memory. TMT B, Clock Drawing Test (CDT), Visual Cognitive Assessment Test (VCAT) were used to evaluate executive function.

\subsection{Statistical Analysis}

Data analysis was performed using IBM $^{\circledR}$ SPSS $^{\circledR}$ Statistics version 23.0 program. Results were expressed in median for quantitative variables and in number and percentage for qualitative ones. Statistical calculations were conducted in order to compare demographical, clinical and behavioral data between groups. Data were analyzed with Mann Whitney. The possible effect on cognitive functions was assessed with a significance level of $\mathrm{p}<0.05$.

\section{RESULTS}

The patient group consisted of 17 (42.50\%) male and 23 $(57.50 \%)$ female patients. The median patient age was 20.50 years old. The median years of education were 11 years. There was no statistically significant difference between the two groups regarding age, sex and years of education (Table 1). The p-value for age and education level was assessed with Mann-Whitney while gender was assessed with chi-square.

Table 1. Demographic data of thalassemia patients and healthy controls.

\begin{tabular}{|c|c|c|c|}
\hline Characteristic & $\begin{array}{c}\text { Thalassemia } \\
(\boldsymbol{n}=\mathbf{4 0})\end{array}$ & $\begin{array}{c}\text { Control } \\
(\boldsymbol{n}=\mathbf{4 0})\end{array}$ & $\boldsymbol{\rho}$-value \\
\hline Gender & & & \\
\hline Male & $17(42.5 \%)$ & $15(37.5 \%)$ & 0.648 \\
\hline Female & $23(57.5 \%)$ & $25(62.5 \%)$ & \\
\hline Age (years) & & & 0.070 \\
\hline Median & 20.50 & 20.50 & \\
\hline Range & $32(15-47)$ & $34(14-48)$ & \\
\hline Years of Education & & & 0.881 \\
\hline Median & 11 & 12 & \\
\hline Range & $14(2-16)$ & $10(6-16)$ & \\
\hline
\end{tabular}

From Table 2, the results of VCAT and ADAS-Cog from both groups can be observed. The ADAS-Cog score for the thalassemia group was significantly lower than the control group, while there was no statistically significant difference in the VCAT score.

Table 2. Differences of VCAT and ADAS-Cog between two groups.

\begin{tabular}{|c|c|c|c|}
\hline Variables & Thalassemia $(\boldsymbol{n}=\mathbf{4 0})$ & Control $(\boldsymbol{n}=\mathbf{4 0})$ & $\boldsymbol{\rho}$-value \\
\hline Global & & & \\
\hline V CAT & & & 0.084 \\
\hline Median & 27.50 & 5.00 & \\
\hline Range (min-max) & $12(18-30)$ & $3(2-5)$ & \\
\hline ADAS-Cog & & & $0.014 *$ \\
\hline Mean & $6.127 \pm 3.286$ & $4.452 \pm 1.72$ & \\
\hline Median & 5.30 & 4.3 & \\
\hline Range (min-max) & $14(2-16)$ & $7.40(1,60-9.00)$ & \\
\hline
\end{tabular}

VCAT $=$ Visual Cognitive Assessment Test, ADAS-Cog= Alzheimer's Disease Assessment Scale-Cognitive Subscale

From Table 3, it can be seen that the thalassemia group had poor outcomes in the attention, verbal memory and executive function domain compared to the control group. Table $\mathbf{3}$ shows the p-value of the vigilance and digit symbol as 0.022 and $<0.001$. The $p$-value for word list recall and logical memory is shown as 0.026 and 0.001 , while p-value of TMT-B and CDT is 0.042 and 0.049 . 
Table 3. Neuropsychology test of thalassemia patients and control group.

\begin{tabular}{|c|c|c|c|}
\hline Variables & Thalassemia $(n=40)$ & Control $(n=40)$ & $\rho$-value \\
\hline \multicolumn{4}{|l|}{ Attention } \\
\hline TMT A & & & 0.350 \\
\hline Median & 41 & 38.50 & \\
\hline Range (min-max) & $46(20-66)$ & $55(15-70)$ & \\
\hline \multicolumn{4}{|l|}{ Vigilance } \\
\hline Omission & & & $0.022 *$ \\
\hline Median & 00.00 & 0 & \\
\hline Range (min-max) & $2(0-2)$ & 0 & \\
\hline Commission & & & 0.155 \\
\hline Median & 00.00 & 0 & \\
\hline Range (min-max) & $1(0-1)$ & 0 & \\
\hline Digit Span & & & 0.370 \\
\hline Median & 5 & 5 & \\
\hline Range (min-max) & $6(2-8)$ & $3(4-7)$ & \\
\hline Digit Symbol & & & $<0.001 * * *$ \\
\hline Median & 45.50 & 59.50 & \\
\hline Range (min-max) & $41(25-66)$ & $47(34-81)$ & \\
\hline \multicolumn{4}{|l|}{ Language } \\
\hline Verbal Fluency & & & 0.791 \\
\hline Median & 20.00 & 21.00 & \\
\hline Range (min-max) & $19(13-32)$ & $30(3-33)$ & \\
\hline Boston Naming & & & 0.961 \\
\hline Median & 14.00 & 14.00 & \\
\hline Range (min-max) & $4(11-15)$ & $10(5-15)$ & \\
\hline \multicolumn{4}{|l|}{ Verbal Memory } \\
\hline Word List Task & & & 0.367 \\
\hline Median & 23.00 & 23.50 & \\
\hline Range (min-max) & $14(13-27)$ & $13(15-18)$ & \\
\hline Word List Recall & & & $0.026^{*}$ \\
\hline Median & 9.00 & 9.00 & \\
\hline Range (min-max) & $5(5-10)$ & $6(4-10)$ & \\
\hline Word List Recognition & & & 0.317 \\
\hline Median & 10.00 & 10.00 & \\
\hline Range (min-max) & $0(10)$ & $1(9-10)$ & \\
\hline Logical Memory & & & $0.001 * * *$ \\
\hline Median & 9.25 & 12.50 & \\
\hline Range (min-max) & $13.50(2.5-16)$ & $14.00(5.50-19.50)$ & \\
\hline \multicolumn{4}{|l|}{ Visual Memory } \\
\hline Recall Constructional & & & 0.075 \\
\hline Median & 14.00 & 14.00 & \\
\hline Range (min-max) & $10(4-14)$ & $7(7-14)$ & \\
\hline \multicolumn{4}{|l|}{ Visuospatial } \\
\hline Constitutional Praxis & & & 0.105 \\
\hline Median & 11.00 & 11.00 & \\
\hline Range (min-max) & $4(7-11)$ & $18(4-22)$ & \\
\hline Block Design & & & 0.011 \\
\hline Median & 4.00 & 4.00 & \\
\hline Range (min-max) & $4(0-4)$ & 0 & \\
\hline DTCT & & & 0.282 \\
\hline Median & 8.00 & 8.00 & \\
\hline Range (min-max) & $6(3-9)$ & $2(7-9)$ & \\
\hline Executive Function & & & \\
\hline
\end{tabular}


(Table $\square$ ) contd.....

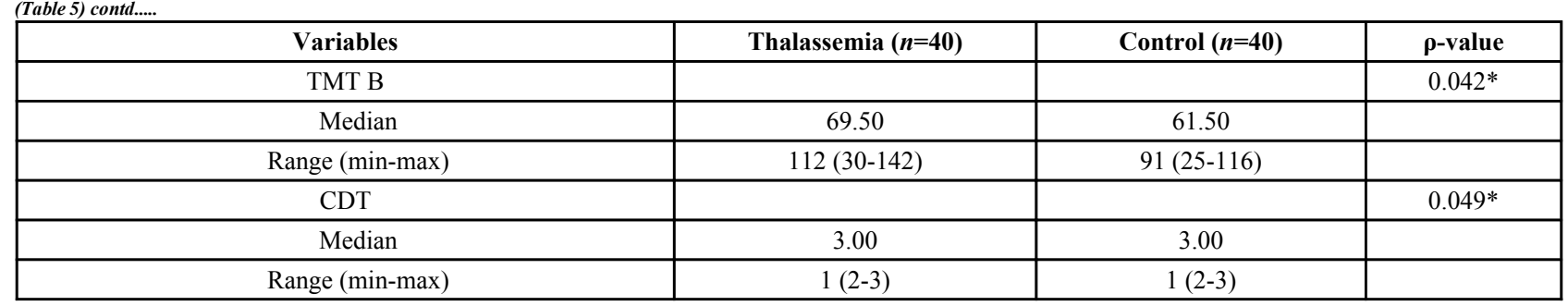

CDT $=$ Clock Drawing Test, DTCT $=$ Drawing To Command Test, TMT $=$ Trail Making Test.

\section{DISCUSSION}

Our study showed that thalassemia patients had cognitive impairment compared with the control group. From the various neuropsychological tests that were used in this study, the thalassemia group showed to be statistically lower especially in attention, verbal memory and executive function.

Previous studies regarding cognitive status have been done on thalassemia patients. [12 - 15]. In most studies, thalassemia patients had impaired cognitive function but the impacts on daily life activities were subclinical and usually discovered by comprehensive neuropsychology tests. Monastero et al. conducted the first few studies assessing cognitive functioning in beta-thalassemia patients. From 46 beta-thalassemia major patients and 46 controls, a significantly impaired cognitive function was shown in the former based on all neuropsychological batteries [12].

The study by Ahmadpanah et al. showed that patients with minor beta-thalassemia did not display impaired cognitive performance compared to healthy controls. Hemoglobin levels or gender were also unrelated, but years of education were strongly associated with the level of cognitive performance. From the data, it was shown that individuals with minor betathalassemia did not perform poorly on the cognitive test when compared to healthy controls. Even though they did present a causal relationship between the length of education and higher cognitive performance; it is possible that a person with more extended academic achievement has better cognitive knowledge and superior performance than others [16].

Other studies by Zangiabadi et al. and Nevruz et al. reported impairment of cognitive abilities in minor betathalassemia patients leading to cognitive deficits [8, 17].

Zangiabadi et al. found lower performances in patients with minor beta-thalassemia in subtests of arithmetic and vocabulary and picture completion. However, both Zangiabadi et al. and Monastero et al. did not evaluate the length of education levels $[12,17]$.

Attention system is anatomically separate from processing systems, which handle incoming stimuli, make decisions, and produce outputs. Active attention is a multidimensional cognitive process that includes the ability to select and focus on what is important at any given moment, the ability to consistently maintain mental effort while performing tasks that require mental energy and the ability to inhibit action or thought while previewing alternative actions or thoughts. The alerting network is modulated by the brain's norepinephrine system and involves major nodes in the frontal and parietal cortex. The alert state is critical to high-level performance. The orienting network interacts with sensory systems to improve the priority of information relevant to task performance. The orienting network exerts much of the control over other brain networks during infancy and early childhood. While the executive network is involved in resolving competing actions in tasks where there is conflict. The executive network includes the anterior cingulate cortex, anterior insula, areas of the mid prefrontal cortex, and the underlying striatum [18 - 21].

Memory is a general term for a mental process that allows the individual to store information for later recall. Memory has three stages, which include received and registered, storing or retaining and recall or retrieval. Each stage in the total memory process relies on the integrity of the previous stages. Any interruption in the hierarchy may prevent the storage or retrieval of a memory [22]. Strien et al. explained that each parahippocampal and hippocampal sub-region contributes uniquely to the encoding, consolidation and retrieval of declarative memories [23]. Opitz also explained the role of medial temporal lobe sub-regions, especially of the hippocampus in memory. The hippocampus and the parahippocampal cortex were assumed to support recollection, i.e. recognition of an item on the basis of the retrieval of specific contextual details of the previous learning experience, whereas the perirhinal cortex subserves familiarity, i.e. item recognition on the basis of a scalar memory strength but without retrieval of any specific detail about the study episode [24].

Takeuchi et al. stated that executive functions involve control processes such as goal-oriented planning, flexible strategy generation, sustaining set maintenance, selfmonitoring, and inhibition [25]. Executive functions have been associated with functions of the prefrontal cortex in the brain [26-28].

The study by Kharat and Waghmare showed that individuals having anemia were more vulnerable to inattentiveness, delayed information analysis, late decision making and slow processing of working memory as compared to the control group [29]. Nemtsas also mentioned that chronic hypoxia and iron overload contribute to neurological manifestations in beta-thalassemia [4].

Iron participates in a wide array of cellular functions and is essential for normal neural development and physiology. But if inappropriately managed, the transition metal is capable of generating neurotoxic reactive oxygen species $[30,31]$. In spite of improvements in transfusion practices and the availability of effective iron chelators, the life of thalassemia patients is punctuated by frequent complications. Repeated transfusions and also inadequate chelation can cause patients to have a high level of ferritin serum that leads to iron deposition in the body $[32,33]$. But the evidence of iron brain deposition in beta- 
thalassemia patients has never been studied extensively.

Patients with thalassemia have a high prevalence of being in a hypercoagulable state. This is because of the profound hemostatic changes. The presence of a higher than normal incidence of thromboembolic events and the existence of prothrombotic hemostatic anomalies in the majority of the patients have led to the recognition of the existence of a chronic hypercoagulable state in thalassemia patients. Hypercoagulable state in thalassemia can lead to cerebral injury that may interfere with cognitive function in thalassemia patients [34 - 37].

Unfortunately, this study did not assess the depression level between the two groups. In several studies, cognitive symptoms have shown greater impact, because cognition is fundamental to patients' everyday life. Deficits of cognition may impact psychosocial and workplace engagement. Low mood and cognitive impairment are associated with poor psychosocial functioning [38, 39].

Our study did not assess the Intelligence Quotient (IQ) level of each subject in both groups. Prior assessment of the IQ level may add further information on the cognitive abilities of a person. Subjects can score better if they have IQ up to about 90 or 95 but those cannot improve further whose IQs exceed this range [40 - 42].

The use of iron chelation agents also has an impact on cognition. Deferoxamine (DFO), a clinically used iron chelator, was studied in a mouse model of surgery-induced cognitive dysfunction and its neuroprotective effects on neuroinflammation, oxidative stress, and memory function were assessed. Treatment with an iron chelator, DFO, prevented memory dysfunction in this model by restoring iron homeostasis, neuroinflammation, and oxidative stress [43]. Other chelator agents such as Deferasirox and Deferiprone can also reduce iron burden in transfused patients with thalassemia [44]. Combination of deferasirox and deferoxamine was more effective than deferasirox alone for decreasing iron burden [45].

\section{CONCLUSION}

Patients with thalassemia had lower cognitive function especially in domains of attention, verbal memory and executive function compared to the control group. Further research needed to assess intervention could be used to produce better outcomes for thalassemia patients.

\section{ETHICS APPROVAL AND CONSENT TO PARTICIPATE}

The protocol of the study was approved by the Instituitional Ethics Committe of Universitas Padjadjaran, Indonesia under approval number 66A/UN6.C.10/PN/2017.

\section{HUMAN AND ANIMAL RIGHTS}

No Animals were used in this research. All human research procedures followed were in accordance with the ethical standards of the committee responsible for human experimentation (institutional and national), and with the Helsinki Declaration of 1975, as revised in 2013.

\section{CONSENT FOR PUBLICATION}

Written informed consent was obtained prior to participation in the study.

\section{AVAILABILITY OF DATA AND MATERIALS}

Not applicable.

\section{FUNDING}

This study is funded by Universitas Padjadjaran, Bandung, Indonesia under grant number 872/UN6.3.1/LT/2017.

\section{CONFLICT OF INTEREST}

The authors declare no conflict of interest, financial or otherwise.

\section{ACKNOWLEDGEMENTS}

Declared none.

\section{REFERENCES}

[1] Rund D. Thalassemia 2016: Modern medicine battles an ancient disease. Am J Hematol 2016; 91(1): 15-21.

[http://dx.doi.org/10.1002/ajh.24231]

[2] Maharani EA, Soedarmono YSM, Nainggolan IM. Frequency of thalassemia carrier and $\mathrm{Hb}$ variant and the quality of stored donor blood. Med J Indones 2015; 23(4): 209.

[http://dx.doi.org/10.13181/mji.v23i4.766]

[3] Yacobovich J, Tamary H. Thalassemia major and sickle cell disease in adolescents and young adults. Acta Haematol 2014; 132(3-4): 340-7. [http://dx.doi.org/10.1159/000360235]

[4] Nemtsas P, Arnaoutoglou M, Perifanis V, Koutsouraki E, Orologas A. Neurological complications of beta-thalassemia. Ann Hematol 2015; 94(8): 1261-5.

[http://dx.doi.org/10.1007/s00277-015-2378-z]

[5] Elhabiby MM, ElSalakawy W, Khalil SA, Hassan DI, Hjislam SG. Cognitive dysfunction in $\beta$-thalassemia major and intermedia patients and its clinical correlates. Middle East Curr Psychiatry [Internet] 2016; 23(3): 128-33. Available from: http://content.wkhealth.com/linkback/openurl?sid=WKPTLP:landingp age \&an=01438246-201607000-0000310.1097/01.XME.0000484344.4 9943.1c

[6] Cappellini MD, Musallam KM, Marcon A, Taher A. Coagulopathy in Beta-Thalassemia: Current Understanding and Future Perspectives. Mediterr J Hematol Infect Dis 2009; 1http://www.mjhid.org/article/view/5250 [Internet].

[http://dx.doi.org/10.4084/MJHID.2009.029]

[7] Duman O, Arayici S, Fettahoglu C, et al. Neurocognitive function in patients with $\beta$-thalassemia major. Pediatr Int 2011; 53(4): 519-23.http://www.ncbi.nlm.nih.gov/pubmed/20964788 [Internet]. [http://dx.doi.org/10.1111/j.1442-200X.2010.03279.x]

[8] Nevruz O, Ulas U, Cetin T, Kutukcu Y, Kurekci A. Cognitive dysfunction in b -thalassemia minor. 2007; 207: pp. 203-7.

[9] Vitrano A, Calvaruso G, Lai E, et al. The era of comparable life expectancy between thalassaemia major and intermedia: Is it time to revisit the major-intermedia dichotomy? $\mathrm{Br} \mathrm{J}$ Haematol 2016; 2017(176): 124-30.

[10] S. R. A. K, O. D. Cognitive functions in adults with beta-thalassemia major: Before and after blood transfusion and comparison with healthy controls. Ann N Y Acad Sci 2016; 1375(1): 19-27.http://www.blackwellpublishing.com/0077-8923\%5Cnhttp://ovi dsp.ovid.com/ovidweb.cgi? $=$ JS \&PAGE $=$ reference $\& D=$ emed $18 \mathrm{~b} \& \mathrm{~N}$ EWS $=\mathrm{N} \& A N=611568078$ [Internet].

[http://dx.doi.org/10.1111/nyas.13103]

[11] Siddiqui SH, Ishtiaq R, Sajid F, Sajid R. Quality of life in patients with thalassemia major in a developing country. J Coll Physicians Surg Pak 2014; 24(7): 477-80.

[12] Monastero R, Monastero G, Ciaccio C, Padovani A, Camarda R. Cognitive deficits in beta-thalassemia major. Acta Neurol Scand 2000; 102(3):

162-8.http://doi.wiley.com/10.1034/j.1600-0404.2000.102003162.x 
[Internet]

[http://dx.doi.org/10.1034/j.1600-0404.2000.102003162.x]

[13] Gamayani U, Gartika P, Meidha LP, Cahyani A, Aminah S, Panigoro R. Attention and executive function impairment in children with betathalassaemia major. J Biomed Clin Sci 2017; 2(2): 57-9.

[14] Gamayani U, Meidha Dini Lestari NL, Ganiem AR, Panigoro R. Influence of working memory on academic achievement and quality of life in children with beta-thalassemia major. Open Psychol J 2019; 12(1):

76-83.https://openpsychologyjournal.com/VOLUME/12/PAGE/76/ [Internet]

[http://dx.doi.org/10.2174/1874350101912010076]

[15] Raafat N, El Safy U, Khater N, et al. Assessment of cognitive function in children with beta-thalassemia major: A cross-sectional study. J Child Neurol 2015; 30(4): 417-22.

[http://dx.doi.org/10.1177/0883073814550827]

[16] Ahmadpanah M, Asadi Y, Haghighi M, Ghasemibasir H, Khanlarzadeh E, Brand S. In patients with minor beta-thalassemia, cognitive performance is related to length of education, but not to minor beta-thalassemia or hemoglobin levels. Iran J Psychiatry 2019; 14(1): 47-53.

[http://dx.doi.org/10.18502/ijps.v14i1.422]

[17] Zangiabadi N, Yarahmadi F, Darekordi A, Shabani M, Dadgar MM. Comparison between $\beta$-Thalassemia minor and normal individuals using the wechsler adult intelligence scale. Hemoglobin 2013; 37(5): 467-76.

[http://dx.doi.org/10.3109/03630269.2013.806330]

[18] Petersen SE. The attention system of the human brain. Neurology 1990; 25-42.

[19] Posner MI, Rothbart MK, Sheese BE, Voelker P. Developing attention: behavioral and brain mechanisms. Adv Neurosci (Hindawi) 2014; 2014: 1-9.https://www.hindawi.com/archive/2014/405094/ [Internet].

[http://dx.doi.org/10.1155/2014/405094]

[20] Lael Siler T. Neurotranslations: interpreting the human brain's attention system. AIMS Med Sci 2016; 3(2): 179-202.http://www.aimspress.com/article/10.3934/medsci.2016.2.179 [Internet].

[http://dx.doi.org/10.3934/medsci.2016.2.179]

[21] Petersen SE, Posner MI. The attention system of the human brain: 20 years after. Annu Rev Neurosci 2012; 73-89.

[http://dx.doi.org/10.1146/annurev-neuro-062111-150525]

[22] Strub RL, Black FW. The Mental Status Examination in Neurology. 2nd ed. Philadelphia: F.A. Davis Company 2000.https://books.google.co.id/books?id=TN7CQgAACAAJ Internet

[23] Van Strien NM, Cappaert NLM, Witter MP. The anatomy of memory: An interactive overview of the parahippocampal- hippocampal network. Nat Rev Neurosci 2009; 10(4): 272-82.

[http://dx.doi.org/10.1038/nrn2614]

[24] Opitz B. Memory function and the hippocampus.The Hippocampus in Clinical Neuroscience. Basel: Kager 2014; pp. 51-9.

[http://dx.doi.org/10.1159/000356422]

[25] Takeuchi H, Taki Y, Sassa Y, Hashizume H, Sekiguchi A, Fukushima A, et al. Brain structures associated with executive functions during everyday events in a non-clinical sample. Brain Struct Funct 2013; 218: 1017-32.

[http://dx.doi.org/10.1007/s00429-012-0444-z]

[26] Stuss DT. Functions of the frontal lobes: relation to executive functions. J Int Neuropsychol Soc 2011; 17(05): 759-65.http://www.journals.cambridge.org/abstract_S1355617711000 695 [Internet]

[http://dx.doi.org/10.1017/S1355617711000695]

[27] Stuss DT, Alexander MP. Executive functions and the frontal lobes: A conceptual view. Psychol Res 2000; 63(3-4): 289-98.http://link.springer.com/10.1007/s004269900007 [Internet]. [http://dx.doi.org/10.1007/s004269900007]

[28] Di X, Rypma B, Biswal BB. Correspondence of executive function related functional and anatomical alterations in aging brain. Prog Neuropsychopharmacol Biol Psychiatry 2014; 48: 41-50. [Internet]. [http://dx.doi.org/10.1016/j.pnpbp.2013.09.001]

[29] Kharat P, Waghmare P. Could anemia be the reason for dysfunctional cognition??? 2015; 3(3): 663. Available from: http://www.scopemed.org/?mno=177793

30] Schipper HM. Brain iron deposition and the free radical-mitochondrial theory of ageing. Ageing Res Rev 2004; 3(3): 265-301 [http://dx.doi.org/10.1016/j.arr.2004.02.001]

[31] Schipper HM. Neurodegeneration with brain iron accumulation Clinical syndromes and neuroimaging. Biochim Biophys Acta Mol Basis Dis 2012; 1822(3): 350-60. [Internet]. [http://dx.doi.org/10.1016/j.bbadis.2011.06.016]

[32] Prakash A, Aggarwal R. Thalassemia major in adults: Short stature, hyperpigmentation, inadequate chelation, and transfusion-transmitted infections are key features. N Am J Med Sci 2012; 4(3): 141-4.

[http://dx.doi.org/10.4103/1947-2714.93886]

[33] Borgna-Pignatti C, Cappellini MD, De Stefano P, Del Vecchio GC, Forni GL, Gamberini MR, et al. Survival and complications in thalassemia. Ann N Y Acad Sci 2005; 1054: 40-7.

[http://dx.doi.org/10.1196/annals.1345.006]

[34] Musallam KM, Taher AT, Karimi M, Rachmilewitz EA. Cerebral infarction in $\beta$-thalassemia intermedia: Breaking the silence. Thromb Res 2012; 130(5): 695-702. [Internet].

[http://dx.doi.org/10.1016/j.thromres.2012.07.013]

[35] Eldor A, Rachmilewitz EA. The hypercoagulable state in thalassemia. Blood 2002; 99(1): 36-43.

[http://dx.doi.org/10.1182/blood.V99.1.36]

[36] Nakashima MO, Rogers HJ. Hypercoagulable states: An algorithmic approach to laboratory testing and update on monitoring of direct oral anticoagulants. Blood Res 2014; 49(2): 85-94.

[http://dx.doi.org/10.5045/br.2014.49.2.85]

[37] Ansari B, Saadatnia M, Asghar Okhovat A. Watershed infarct in betathalassemia major patient. Case Rep Neurol Med 2017; 20172736402http://www.ncbi.nlm.nih.gov/pubmed/28428899\%5Cnhtt p://www.pubmedcentral.nih.gov/articlerender.fcgi?artid=PMC538591 3 [Internet].

[http://dx.doi.org/10.1155/2017/2736402]

[38] Baune BT, Malhi GS, Morris G, Outhred T, Hamilton A, Das P, et al. Cognition in depression: Can we THINC-it better? J Affect Disord 2017; 2018(225): 559-62.

[39] Rock PL, Roiser JP, Riedel WJ, Blackwell AD. Cognitive impairment in depression: A systematic review and meta-analysis. Psychol Med 2014; 44(10): 2029-40.

[http://dx.doi.org/10.1017/S0033291713002535]

[40] Diaz-Asper CM, Schretlen DJ, Pearlson GD. How well does IQ predict neuropsychological test performance in normal adults? J Int Neuropsychol Soc 2004; 10(1): 82-90.

[http://dx.doi.org/10.1017/S1355617704101100]

[41] Mohn C, Sundet K, Rund BR. The relationship between IQ and performance on the MATRICS consensus cognitive battery. Schizophr Res Cogn 2014; 1(2): 96-100. [Internet]. [http://dx.doi.org/10.1016/j.scog.2014.06.003]

[42] Checa P, Fernández-Berrocal P. The role of intelligence quotient and emotional intelligence in cognitive control processes. Front Psychol 2015; 6(DEC): 1-8.

[http://dx.doi.org/10.3389/fpsyg.2015.01853]

[43] Li Y, Pan K, Chen L. Deferoxamine regulates neuroinflammation and iron homeostasis in a mouse model of postoperative cognitive dysfunction. J Neuroinflammation 2016; 13(1): 1-12. [Internet]. [http://dx.doi.org/10.1186/s12974-016-0740-2]

[44] Xia S, Zhang W, Huang L, Jiang H. Comparative efficacy and safety of deferoxamine, deferiprone and deferasirox on severe thalassemia: A meta-analysis of 16 randomized controlled trials. PLoS One 2013; 8(12): $1-9$.

[http://dx.doi.org/10.1371/journal.pone.0082662]

[45] Eghbali A, Shokri P, Afzal RR, Bagheri B. A 1-year randomized trial of deferasirox alone versus deferasirox and deferoxamine combination for the treatment of iron overload in thalassemia major. Transfus Apher Sci [Internet] 2019; 58(4): 429-33. [http://dx.doi.org/10.1016/j.transci.2019.03.021] 